\title{
Cryopreservation of Shoot Tips of "Brazilian Ginseng" (Pfaffia glomerata (Spreng.) Pedersen) by Vitrification
}

\author{
Daniela Vasconcelos de Oliveira ${ }^{1}$, Izulmé Rita Imaculada Santos ${ }^{2}$, Ildeu Soares Martins ${ }^{3}$ \\ \& Antonieta Nassif Salomão ${ }^{2}$ \\ ${ }^{1}$ Brasília, Federal District, Brazil \\ ${ }^{2}$ Embrapa Genetic Resources and Biotechnology, Brasília, Federal District, Brazil \\ ${ }^{3}$ National University of Brasília, Brasília, Federal District, Brazil \\ Correspondence: Izulmé Rita Imaculada Santos, Embrapa Genetic Resources and Biotechnology, Brasília, \\ Federal District, CEP: 70770-917, Asa Norte, Brazil. Tel: 55-613-448-4934. E-mail: izulme.santos@embrapa.br
}

Received: April 16, 2019

doi:10.5539/jas.v11n11p146
Accepted: May 27, 2019 Online Published: July 31, 2019

URL: https://doi.org/10.5539/jas.v11n11p146

\begin{abstract}
Pfaffia glomerata (Amaranthaceae), "Brazilian Ginseng", is a medicinal plant used in folk medicine. Roots are used as a tonic to restore and enhance wellbeing and for treatment of arthritis, gastritis and rheumatism. Conservation of $P$. glomerata germplasm is a priority and cryopreservation is the most promising technique for long-term storage of plant genetic resources. Hence, the objective of this work was to develop a cryopreservation protocol for shoot tips of $P$. glomerata using vitrification techniques. For cryopreservation, shoot tips (ST) from in vitro grown plants were pre-cultured for $19 \mathrm{hr}$ on MS medium containing $0.3 \mathrm{M}$ sucrose, treated with loading and vitrification solutions prior to rapid freezing by direct plunge in liquid nitrogen, rapid thawing on a water bath at $38 \pm 2{ }^{\circ} \mathrm{C}$ and treatment with a dilution solution. Three vitrification solutions (PVS2, PVS3 and PVS4), three exposure times $\left(20 \mathrm{~min} ., 40 \mathrm{~min}\right.$. and $60 \mathrm{~min}$.) and two temperatures $\left(25^{\circ} \mathrm{C}\right.$ and $\left.0{ }^{\circ} \mathrm{C}\right)$ were tested. After cryopreservation, rewarmed shoot tips were inoculated on MS growth medium and the best regeneration percentages were $63 \%, 42 \%$ and $65 \%$ for shoot tips treated with PVS2, PVS3 and PVS4, respectively, for 60 min., at $25{ }^{\circ} \mathrm{C}$. The results obtained show that vitrification with PVS2 and PVS4, at $25{ }^{\circ} \mathrm{C}$, for 60 min were the best treatments for successful cryopreservation of shoot tips of in vitro grown plantlets of P. glomerata and that cryopreservation is suitable for ex situ conservation of the germplasm of this medicinal species.
\end{abstract}

Keywords: cryopreservation, ecdysterone, genetic resources, vitrification solutions

\section{Introduction}

Roots of plants of the genus Pfaffia, Amaranthaceae, known as "Brazilian Ginseng", are used in folk medicine as an herbal remedy for a range of medical conditions. They are used as a tonic to stimulate physical and mental activity and enhance wellbeing, reduce stress, boost energy and memory and as an aphrodisiac (Freitas et al., 2004; Marques et al., 2004; Mendes \& Carlini, 2007; Rates \& Gosmann, 2002). Medical applications as an analgesic and anti-inflammatory for gastritis, arthritis and rheumatism have also been reported (Freitas et al., 2003; Neto et al., 2005). One of the most important species of Brazilian ginseng is Pfaffia glomerata (Spreng.) Pedersen, whose main habitat is the riparian forests of the Central-West region of Brazil and the Paraná River basin. Recent research investigated the effect of hydroalcoholic extracts of P. glomerata roots and found evidence that it protected the gastric mucosa and reduced intestinal inflammation and ulcers (Neto et al., 2005). The adaptogenic effect of this species is attributed to compounds present in the roots, namely $\beta$-ecdysone (ecdysteroid used as a chemical marker of root quality), glomeric acid (triterpenoid), pfameric acid (nortriterpenoid), ecdysterone, rubrosterone, oleanolic acid and $\beta$-glucopyranosil oleanolate (Nakai et al., 1984; Nishimoto et al., 1984; Nishimoto et al., 1987; Nishimoto et al., 1988; Shiobara et al., 1993). The isolation and characterization of active compounds from roots of "Brazilian Ginseng" and the confirmation of their pharmacological properties increased the use of Pfaffia species in natura or in commercial preparations (Leal et al., 2010; Shiobara et al., 1993).

Despite the great phytotherapeutic and economic potential of "Brazilian Ginseng", its domestication and cultivation is limited due to lack of knowledge about seed germination, phenology, seedling production and 
propagation techniques. These problems restrict large-scale production of Pfaffia for pharmaceutical use, and as a result, raw material supply is still dependent on extractivism and predatory collection, resulting in rapid depletion of native populations in natural habitats and increased risk of disappearance of these species. This situation led to the proposal of policies and research actions on several fronts to enable the establishment of sustainable management plans in areas of occurrence and the development of technologies for propagation and germplasm conservation of Pfaffia species. In this context, the development of methodologies for the establishment of ex situ collections of $P$. glomerata germplasm in gene banks, under conditions that guarantee maximum genetic and biological integrity has become a priority.

Cryopreservation is the technology for conservation of biological material at ultra - low temperatures, generally in liquid nitrogen at $-196{ }^{\circ} \mathrm{C}$, or in its vapor phase at $-150^{\circ} \mathrm{C}$ (Engelmann, 2011; Matsumoto, 2017; Santos \& Salomão, 2017). It has become an ideal approach for long-term conservation of plant germplasm because during storage at such temperatures all metabolic activities are suspended, thus preventing biological deterioration and ensuring high genetic stability, while requiring minimal space and maintenance (Matsumoto, 2017; Santos \& Salomão, 2017). Cryopreservation can be applied for the conservation of a variety of plant structures and tissues such as shoot tips, axillary buds, zygotic embryos, somatic embryos, callus and cell suspensions (Matsumoto, 2017). The greatest challenge for successful cryopreservation is to avoid the formation of ice crystals inside the cells during rapid cooling in liquid nitrogen (Sakai \& Engelmann, 2007; Sakai, et al., 1990). Ice crystals cause rupture of cell membranes, resulting in loss of semi-permeability, cellular compartmentation, and structural integrity, leading to cell death (Engelmann, 2011; Panis \& Lambardi, 2005; Sakai et al., 1990; Sakai \& Engelmann, 2007; Santos \& Salomão, 2017). Formation of ice crystals will occur when the cell water content is high, therefore to prevent ice formation cellular water content must be reduced. One of the approaches available to promote cell dehydration and avoid formation of crystalline ice within the cells during cryopreservation is osmotic dehydration induced by treatment with highly concentrated cryoprotectant solutions, called vitrification solutions. Vitrification solutions enable the passage of the water present in the cells directly from the liquid phase to an amorphous solid phase, called a "glass" (Panis \& Lambardi, 2005).

Cryopreservation protocols using vitrification-based techniques have been developed for cell suspensions, callus, shoot apices and somatic and zygotic embryos of many different plant species, including tropical and subtropical species which are not naturally tolerant of ultralow temperatures, with high regrowth rates (Engelmann, 2011; Santos \& Salomão 2017; Suranthra et al., 2012; Vandenbussche et al., 2000; Volk \& Walters, 2006). The most widely used vitrification solution is "plant vitrification solution 2", PVS2 (Sakai et al., 1990). Thus, vitrification-based cryogenic protocols are promising approaches to viabilize long-term storage of valuable plant germplasm. Therefore, the objective of this work was to develop a cryopreservation protocol for shoot tips of $P$. glomerata excised from plantlets growing in vitro using vitrification with three different cryoprotectant solutions.

\section{Materials and Methods}

\subsection{Plant Material}

Young branches collected from adult plants of one genotype of $P$. glomerata, accession 2209-09, growing in the field collection of medicinal plants of Embrapa Genetic Resources and Biotechnology, Brasília, DF, Brazil, were the source of explants for this study. Branches were stored in a glass jar containing sterile distilled water, and the jar was closed with a lid until arrival at the Laboratory of Plant Cryobiology where all the experiments described were carried out. In the laboratory, leaves were clipped out of the branches, and they were divided into $5.0 \mathrm{~cm}$ long segments and disinfected with a solution containing sodium hypochlorite (2.0-2.5\% active chlorine), streptomycin (ml) and "Tween 20" (1.0 ml).

\subsection{Establishment and Multiplication of stock Cultures in vitro}

Nodal segments (NS, $0.5 \mathrm{~cm}$ long) containing two lateral buds were excised from disinfected branches and innoculated into glass tubes $(25 \times 150 \mathrm{~mm})$ containing $10 \mathrm{ml}$ of MS culture medium (Murashige \& Skoog, 1962) without growth regulators, supplemented with $3 \%$ sucrose and solidified with $0.7 \%$ agar. The $\mathrm{pH}$ of the medium was 5.7, adjusted prior to autoclaving at $121{ }^{\circ} \mathrm{C}, 1.5$ at, for $20 \mathrm{~min}$. The cultures were maintained in a growth room at $25 \pm 2{ }^{\circ} \mathrm{C}$, under $16 \mathrm{~h}$ photoperiod, with a light intensity of $40 \mu \mathrm{m} \mathrm{m}^{-2} \mathrm{~s}^{-1}$ supplied by white LED tubes. In vitro multiplication to obtain the stock of plantlets needed for the cryopreservation experiments was carried out by subculture of shoot tips (ST) and NS collected from plantlets obtained in vitro on the same growth medium, without growth regulators, and cultivated under the same growth conditions described previously. 


\subsection{Nodal Segments Subculture and Shoot Tips Excision for Cryopreservation}

NS were excised from 30-day-old plantlets growing in vitro on MS basic medium solidified with agar (0.7\%) and transferred to Magenta boxes containing $50 \mathrm{ml}$ of MS medium supplemented with sucrose $(3.0 \%)$, BAP $\left(0.02 \mathrm{mg} \mathrm{L}^{-1}\right)$, ANA $\left(0.01 \mathrm{mg} \mathrm{L}^{-1}\right)$, GA3 $\left(0.1 \mathrm{mg} \mathrm{L}^{-1}\right)$ and solidified with agar $(0.7 \%)$. These cultures were maintained in a growth room under the same growth conditions described above, for 15 days. After 15 days, shoot tips (ST 1.0-2.0 mm long) were isolated from the shoots sprouted on the NS for use in all cryopreservation assays.

\subsection{Cryopreservation Procedures}

To start the cryopreservation trials, ST (1.0-2.0 mm long) were transferred to Petri dishes containing $30 \mathrm{ml}$ of solid pre-culture medium (MS supplemented with $0.3 \mathrm{M}$ sucrose) and cultured overnight (approximately 18 hours), at $25 \pm 2{ }^{\circ} \mathrm{C}$, in the dark. For the vitrification treatments, pre-cultured ST were transferred to cryovials and $2.0 \mathrm{ml}$ of loading solution (LS, MS supplemented with $2.0 \mathrm{M}$ glycerol and $0.4 \mathrm{M}$ sucrose) at room temperature $\left(25 \pm 2{ }^{\circ} \mathrm{C}\right)$ was added to the vial and held for $20 \mathrm{~min}$. at room temperature $\left(25 \pm 2{ }^{\circ} \mathrm{C}\right)$. Subsequently, LS was removed and $2.0 \mathrm{ml}$ of PVS2 vitrification solution (MS supplemented with $30 \%$ glycerol, $15 \%$ ethylene glycol, $15 \%$ DMSO, 0.4M sucrose; Sakai et al., 1990) was added to the vial and held for 20,40 and $60 \mathrm{~min}$. at $25^{\circ} \mathrm{C}$ or at $0{ }^{\circ} \mathrm{C}$. For the treatment with PVS2 at $0{ }^{\circ} \mathrm{C}$, the cryovials containing STs and the PVS2 solution were kept in a Styrofoam box with crushed ice throughout the procedure, and the temperature was monitored with a thermometer. The same vitrification procedures described above were performed using the cryoprotectant solutions PVS3 (MS supplemented with 50\% sucrose and 50\% glycerol) and PVS4 (MS supplemented with 35\% glycerol, 20\% ethylene glycol and $0.6 \mathrm{M}$ sucrose). Eighteen different vitrification treatments, resulting from the combination of three vitrification solutions (PVS2, PVS3 and PVS4), three exposure times (20, 40 and 60 min.) and two temperatures $\left(25^{\circ} \mathrm{C}\right.$ or $\left.0{ }^{\circ} \mathrm{C}\right)$ were tested. The same eighteen vitrification treatments were carried out for control non-frozen ST, resulting in 36 treatments. After each step described here (pre-culture, loading and treatment with each vitrification solution and dilution) samples of 60 ST were transferred to test tubes $(25 \times 150$ $\mathrm{mm}$ ) containing $10 \mathrm{ml}$ of solid basic MS medium and cultivated under the growth conditions described above for regeneration and evaluation. These samples were used as controls. After each vitrification time was completed, PVS2 solution was removed from the cryovials and $2.0 \mathrm{ml}$ of fresh PVS2 solution was added to the same cryovials. Cryovials were capped and plunged directly into liquid nitrogen $\left(\mathrm{LN},-196{ }^{\circ} \mathrm{C}\right)$ for at least $60 \mathrm{~min}$. Cryovials were retrieved from $\mathrm{LN}$ and thawed rapidly in a water bath at $38 \pm 2{ }^{\circ} \mathrm{C}$, with constant shaking, for approximately $1.5 \mathrm{~min}$. Immediately after thawing, PVS2 solution was drained from the vials and $2.0 \mathrm{ml}$ of dilution solution (DS, MS supplemented with $1.2 \mathrm{M}$ sucrose) was added to the vials and held for $60 \mathrm{~min}$, at room temperature $\left(25 \pm 2{ }^{\circ} \mathrm{C}\right)$.

\subsection{Regeneration and Evaluation of Shoot tips}

Thawed ST were immediately transferred into test tubes $(25 \times 150 \mathrm{~mm})$ containing solid basic MS medium for regeneration. The cultures were kept in a growth room at $25 \pm 2{ }^{\circ} \mathrm{C}$, in the dark for $48 \mathrm{~h}$, in diffuse light for 3 days and after that, cultures were maintained under standard growth conditions described above. Samples of $60 \mathrm{ST}$ that underwent all treatments described (excision, pre-culture, loading, vitrification with PVS and dilution) but were not stored in LN were used as controls. These control ST were transferred to test tubes $(25 \times 150 \mathrm{~mm})$ containing $10 \mathrm{ml}$ of solid basic MS medium after each step of the cryopreservation procedure and cultivated under the growth conditions established for this study for regeneration and evaluation.

\subsection{Statistical Analysis}

Statistical design was the factorial, with four factors, type of vitrification solution (PVS2, PVS3 and PVS4), time of exposure to the vitrification solution (20,40 and $60 \mathrm{~min}$.), temperature of treatment with vitrification solution $\left(25^{\circ} \mathrm{C}\right.$ and $0{ }^{\circ} \mathrm{C}$ ) and freezing or not in liquid nitrogen (LN+ and LN-). These 36 treatments (combinations of factors) were replicated six times and the 216 experimental units were arranged in a completely randomized design. For the statistical analysis, the data was submitted to analysis of variance (ANOVA) and the means were compared by the Tukey test at the $1 \%$ probability level $(p=0.01)$. Analyzes were performed using the program GraphPad Prism 5.0 and GENES. Each experiment was performed for 5 days and the regeneration and growth of control (LN-) and frozen ST (LN+) was monitored for up to 60 days.

\section{Results and Discussion}

\subsection{Plant Regeneration From Nodal Segments Innoculated in vitro}

There was no contamination on NS excised from field-grown plants and innoculated in vitro. Normal plantlets with well-developed shoots and roots were produced on $92 \%$ of the NS innoculated (Figure 1). The first signs of 
growth and development of the axillary buds $(\mathrm{AB})$ present in the NS were observed 7 days after innoculation (DAI) (Figure 1A). Fifteen DAI most of the NS already had one or two shoots 1.0 to $1.5 \mathrm{~cm}$ long, and each shoot had at least one pair of fully expanded leaves and one or two roots $0.5-1.0 \mathrm{~cm}$ long (Figure $1 \mathrm{~A}$ and $\mathrm{B}$ ). Within 30 DAI, plantlets exhibited normal morphological appearance, with an average height of $10 \mathrm{~cm}$, a well-developed root system with a main root and smaller secondary roots, and a stem typically divided into 6-8 nodes and internodes (Figure 1C). Nodes characteristically had one pair of laterally expanded leaves, with two axillary buds inserted at the base of the petioles (Figure 1C). Stems and leaves showed predominantly green coloration with pink areas, a pattern that was typical for all the plantlets obtained in vitro (Figure 1C).

In the present study, it was not necessary to make changes to the basic formulation of the MS culture medium, neither supplementation with exogenous growth regulators, activated charcoal or any other type of substance to stimulate establishment of NS in vitro or growth and development of the AB present in these NS. NS excised from thirty-day-old in vitro grown plantlets and subcultured into Magenta boxes containing MS medium supplemented with sucrose (3.0\%), BAP $\left(0.02 \mathrm{mg} \mathrm{L}^{-1}\right)$, ANA $\left(0.01 \mathrm{mg} \mathrm{L}^{-1}\right)$, GA3 $\left(0.1 \mathrm{mg} \mathrm{L}^{-1}\right)$ and solidified with agar $(0.7 \%)$ produced new shoots of similar age and physiological maturity after 15 DAI (Figure 2). Young shoots grown on these NS segments were the source of ST for all cryopreservation experiments (Figure 2B). Preliminary tests (data not shown) were instrumental to determine that two-week-old $\mathrm{AB}$ were ideal for the excision of the ST. Two weeks after subculture of NS, AB elongated and produced shoots 1.0-1.5 cm long with structures differentiated enough to facilitate handling and excision of ST.

Previous publications on micropropagation of $P$. glomerata reported that it was necessary to change the standard formulation of the MS growth medium to obtain in vitro regeneration. Variations in the standard nitrogen, phosphorus and sucrose concentrations, addition of growth regulators such as benzylaminopurine (BAP) and thidiazuron (TDZ) and of activated charcoal were the main modifications reported (Alves et al., 2010; Flores et al., 2009; Flores, et al., 2010; Maldaner et al., 2006; Martins \& Nicoloso, 2004; Nicoloso et al., 2001, 2003). The fast growth and high rates of regeneration observed in the present work demonstrate that basic MS culture medium supplemented only with $3 \%$ sucrose and standard growth conditions is adequate to induce the expression of the organogenic capacity of AB of "Brazilian Ginseng". The in vitro culture procedure reported here is simple and efficient to produce numerous plantlets. Simpler procedures such as this are desirable for the establishment and multiplication in vitro of plant germplasm for use in cryopreservation research because they are practical to replicate, economical and present reduced risk of induction of somaclonal variation during in vitro culture (Matsumoto, 2017).
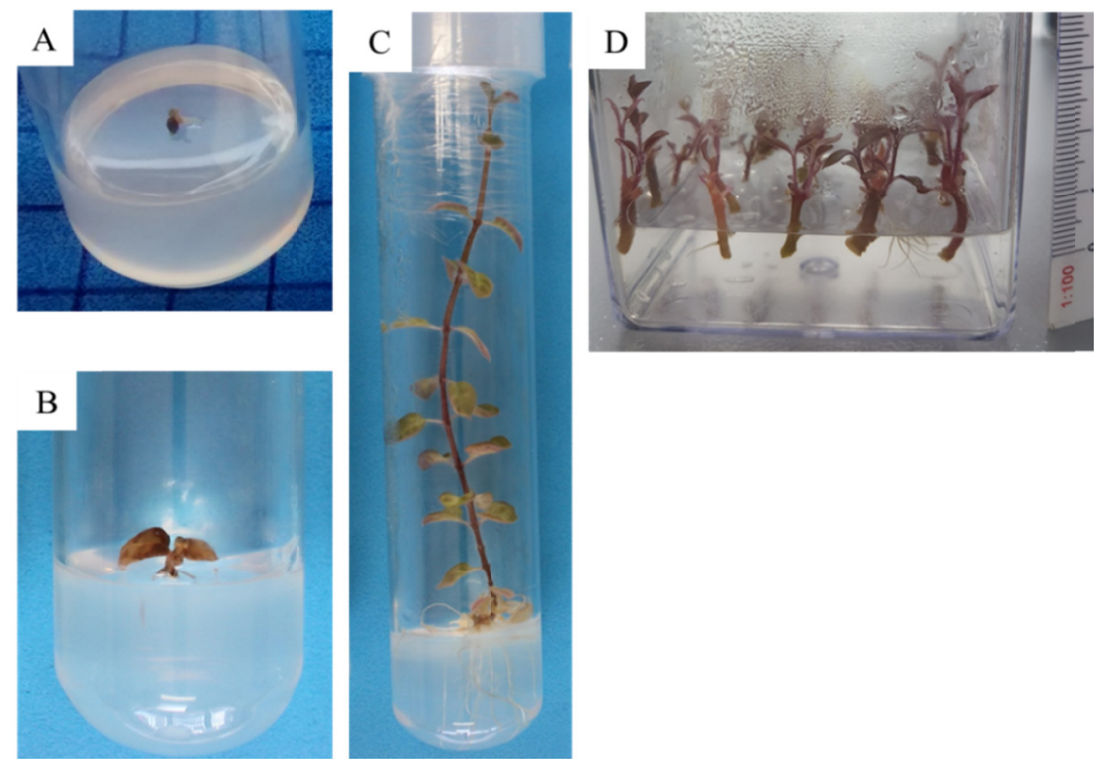

Figure 1. Growth response of Pfaffia glomerata at different stages of the development of the cryopreservation protocol. A-C: axillary buds growing on nodal segment collected from plants growing in the field on basic solid MS medium, 7 (A), 15 (B) and 30 (C) days after introduction in vitro. D: shoots sprouted on nodal segments isolated from in vitro grown plantlets and cultured in MS basic solid medium for $15 \mathrm{~d}$ for the cryopreservation experiments. E: shoot tips (2.0-3.0 mm) isolated from $15 \mathrm{~d}$ old shoots and cultivated overnight (ca. $19 \mathrm{hrs})$ on pre-culture solid MS medium containing 0.4 M of sucrose (Photographs (C: Daniela Vasconcelos Oliveira) 


\subsection{Regeneration of Cryopreserved Shoot Tips}

ST that were pre-cultured and treated only with the loading solution did not survive freezing in liquid nitrogen. Therefore, treatment with a vitrification solution was essential for ST survival and shoot recovery after cryopreservation. Regeneration percentages of ST treated with PVS2, PVS3 and PVS4 at $25^{\circ} \mathrm{C}$ and $0{ }^{\circ} \mathrm{C}$ for 20 , 40 and $60 \mathrm{~min}$ are in Figure 2.

The regeneration percentages of control ST ranged from $92 \%$ to $100 \%$ regardless of the vitrification solution tested and the temperature and duration of the treatment with the vitrification solutions (Figure 2). The highest regeneration percentages after cryopreservation were for ST treated with vitrification solutions at $25{ }^{\circ} \mathrm{C}$, for 60 min (Figure 2). These results indicate that the immersion of P. glomerata ST in vitrification solution for 20 and 40 min probably was not sufficient to promote proper dehydration of these explants. In that case, they probably still had high free water content when exposed to liquid nitrogen, resulting in intracellular ice formation, which is one of the most important factors leading to cryoinjury (Sakai \& Engelmann, 2007). Regeneration percentages of P. glomerata ST treated with PVS2 at $25^{\circ} \mathrm{C}$ and $0{ }^{\circ} \mathrm{C}$ for 20,40 and $60 \mathrm{~min}$ are in Figure 2A. Regeneration of cryopreserved ST treated with PVS2 at $25{ }^{\circ} \mathrm{C}$ for 20,40 and 60 min was $32 \%, 19 \%$ and $63 \%$, respectively (Figure 2A, LN+). Regeneration of non-frozen control ST (LN-) treated with PVS2 at $25{ }^{\circ} \mathrm{C}$ ranged from 99 to $100 \%$, a difference that is not statistically significant $(\mathrm{p} \leq 0.01)$. Regeneration of cryopreserved ST treated with PVS2 at $0^{\circ} \mathrm{C}$ for 20, 40 and $60 \mathrm{~min}$ was 24,20 and $34 \%$, respectively (Figure 2A, LN+). Regeneration of non-frozen controls treated with PVS2 at $0{ }^{\circ} \mathrm{C}$ for 20,40 and 60 min. was 100,100 and $95 \%$, respectively, rates that are not statistically different (Figure $2 \mathrm{~A}, \mathrm{LN}-$ ).

Regeneration percentages of ST treated with PVS3 solution at two different temperatures $\left(0^{\circ} \mathrm{C}\right.$ and $\left.25^{\circ} \mathrm{C}\right)$ for 20 , 40 and 60 min. are in Figure 2B. For ST treated with PVS3 and cryopreserved in liquid nitrogen (LN+, black bars), the highest regeneration rates were $42 \%$ and $25 \%$, attained by ST treated for 60 min with PVS3 at $25^{\circ} \mathrm{C}$ and $0^{\circ} \mathrm{C}$, respectively (Figure 2B). For non-frozen control ST (LN-, clear bars), the regeneration percentages after treatment with PVS3 at $0{ }^{\circ} \mathrm{C}$ for 20, 40, and $60 \mathrm{~min}$ were 97, 100 and $100 \%$, respectively (LN-, clear bars), and after treatment at $25^{\circ} \mathrm{C}$ for 20,40 , and $60 \mathrm{~min}$, were 100,92 and $100 \%$, respectively.

The percentages of regeneration of $P$. glomerata ST after vitrification with PVS4 $0{ }^{\circ} \mathrm{C}$ and $25^{\circ} \mathrm{C}$, for 20,40 and $60 \mathrm{~min}$ are in Figure 2C. Clear bars represent the controls (without freezing, LN-) and the black bars represent the percentages of ST regeneration after cryopreservation in liquid nitrogen $(\mathrm{LN}+)$. Non-frozen ST (LN-, clear bars) showed $100 \%$ regeneration after treatment with PVS4 at $25^{\circ} \mathrm{C}$ for 20,40 , and $60 \mathrm{~min}$. (Figure 2C). For ST submitted to these same treatments and then frozen in liquid nitrogen (LN+, black bars), 53, 44 and $65 \%$ of regeneration percentages were achieved (Figure 2C). Regeneration rates of ST treated with PVS4 solution at $0^{\circ}$ $\mathrm{C}$ for 20, 40 and $60 \mathrm{~min}$ are in Figure 2C. Regeneration was 100\% for non-frozen ST (LN-, clear bars) and 25, 32 and $44 \%$ for frozen ( $\mathrm{LN}+$, black bars).

Shoot tips treated at $25{ }^{\circ} \mathrm{C}$ for $60 \mathrm{~min}$, showed the highest regeneration rates after cryopreservation in liquid nitrogen $(\mathrm{LN}+)$, regardless of the vitrification solution tested. These regeneration rates were statistically different $(\mathrm{P}=0.01)$ from the regeneration rates of shoot tips exposed to other treatments (Figure 2).

ST treated with PVS2 or PVS4 showed better regeneration rates after cryopreservation than those treated with PVS3 (Figure 2). Since PVS2 and PVS4 are more complex vitrification solutions, these results suggest that the combination of sucrose and glycerol, the cryoprotectants present in PVS3, at the concentrations tested were not efficient to promote vitrification and to protect $P$ glomerata cells from ice crystal damage during freezing or warming. 
(A) PVS2

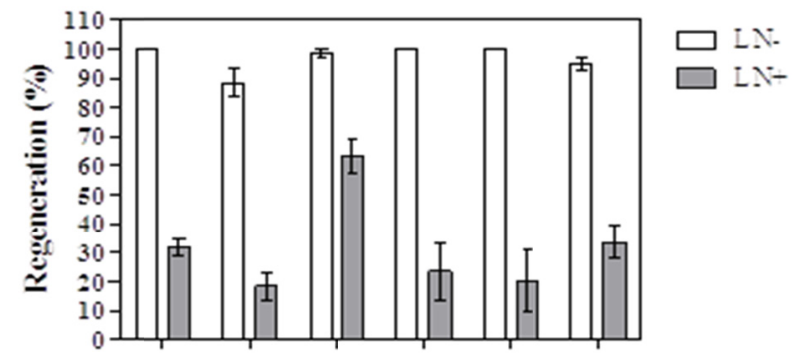

(B) PVS3

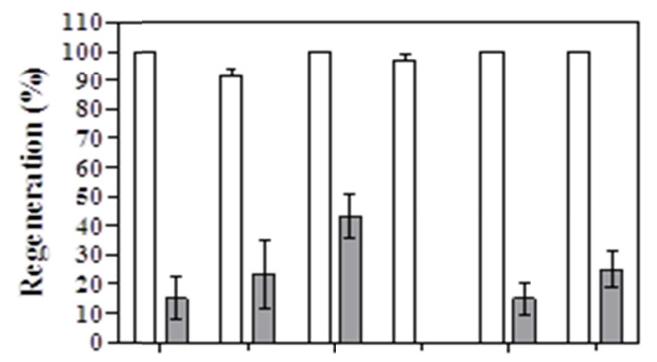

(C) PVS4

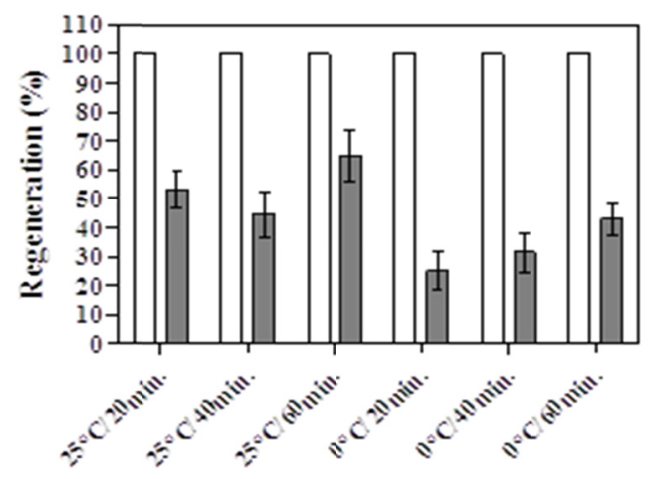

Figure 2. Regeneration percentages of shoot tips of Pfaffia glomerata after vitrification with three solutions, PVS2 (A), PVS3 (B) and PVS4 (C), and cryopreservation in liquid nitrogen. Shoot tips were treated with vitrification solutions at $0^{\circ} \mathrm{C}$ and $25^{\circ} \mathrm{C}$, for 20,40 and $60 \mathrm{~min}$. Black bars show regeneration after cryopreservation ( $\mathrm{LN}+$ ) and clear bars represent regeneration of controls (LN-). Data is presented as means of regeneration percentage with standard error. Means with different letters are significantly different at $\mathrm{P}=0.01$

Previous studies have shown that glycerol is an efficient cryoprotectant, capable of permeating cell membranes, thus fulfilling its vitrifying role of preventing ice crystals formation inside the cells. These studies have also shown that it was more efficient when applied at $25{ }^{\circ} \mathrm{C}$ and when used at $0{ }^{\circ} \mathrm{C}$ glycerol could not permeate the plasma membrane and was not as efficient to promote vitrification (Best, 2015; Fahy, 2010). The current study shows a similar trend, since ST treated with PVS3 at $0{ }^{\circ} \mathrm{C}$ had lower regeneration percentages than those treated with PVS2 and PVS4 at the same temperature, regardless of the duration of the treatment, as can be observed in Figure 2B.

Cryopreserved ST cultured on recovery medium resumed growth within 1-2 wk, regardless of the treatment. The first sign of shoot growth was evident by greening of the explant within seven days after innoculation, followed by leaf expansion and shoot elongation within fifteen days after innoculation. Some surviving ST developed into calluses instead of growing into typical shoots. These results are not included in the survival rates reported here. Callus growth on cryopreserved explants is an indication of cryoinjury and is undesirable because it might result in genetic changes, which is a great concern for researchers (Charoensub et al., 2004; Harding \& Staines, 2001; Matsumoto, 2017). In such cases, it is recomended to optimize the cryopreservation technique tested to provide higher regrowth of explants after thawing without callus growth (Sakai \& Engelmann, 2007). 
Figure 3 shows plantlets obtained from ST treated with vitrification solutions PVS2, PVS3 or PVS4 at two different temperatures $\left(0{ }^{\circ} \mathrm{C}\right.$ and $\left.25{ }^{\circ} \mathrm{C}\right)$, for $60 \mathrm{~min}$, before cryopreservation in liquid nitrogen. Plantlets obtained from cryopreserved ST treated with PVS2 vitrification solution are in Figure 3A and D; Figures 3B and E show plantlets obtained from ST treated with PVS3 and Figure 3C and F show plantlets obtained from ST that underwent vitrification treatment with PVS4 solution. Within 15 DAI, plantlets exhibited normal morphological appearance, with a stem typically divided into nodes and internodes, an average height of $2.0 \mathrm{~cm}$ and a root system with a main root $0.5-1.0 \mathrm{~cm}$ long and smaller secondary roots. Nodes characteristically had one pair of laterally expanded leaves, with axillary buds inserted at the base of the leaf petioles. Stems and leaves showed predominantly green coloration with pink areas, a pattern that is typical for all P. glomerata plantlets growing in vitro.
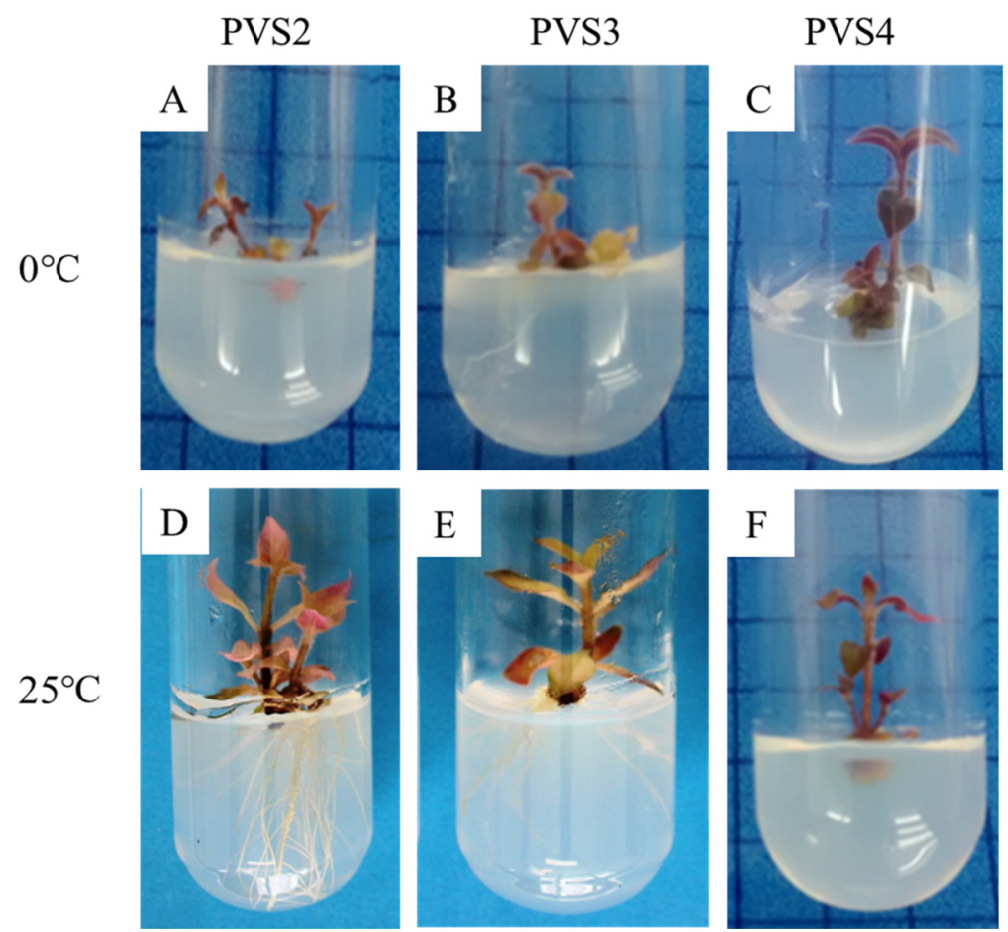

Figure 3. Plantlets developed from shoot tips of Pfaffia glomerata successfully cryopreserved by vitrification. A-PVS2, $0{ }^{\circ} \mathrm{C}$, for $60 \mathrm{~min}$; B-PVS3, $0{ }^{\circ} \mathrm{C}, 60 \mathrm{~min}$; C-PVS4, $0{ }^{\circ} \mathrm{C}, 60 \mathrm{~min}$.; D-PVS2, $25^{\circ} \mathrm{C}, 60 \mathrm{~min}$.; E-PVS3, $25{ }^{\circ} \mathrm{C}, 60 \mathrm{~min}$.; F-PVS4, $25^{\circ} \mathrm{C}, 60 \mathrm{~min}$. (Photographs $\mathbb{C}$ : Daniela Vasconcelos de Oliveira)

Cryopreservation is currently one of the most relevant strategies for long-term conservation of plant genetic resources (Santos \& Salomão, 2017). In the particular case of species clonally propagated or that have seeds that are recalcitrant to storage, cryopreservation is becoming increasingly more relevant. Recent breakthroughs in cryoprotective methodologies are allowing a wider application of cryopreservation in plant genetic resources conservation and storage of clonal materials in liquid nitrogen as a base collection is now the goal of many genebanks (Matsumoto, 2017; Reed, 2008; Santos \& Salomão, 2017).

Recent work has focused on the development of efficient, reliable and simple cryopreservation protocols for long-term storage of plant genetic resources with high biological integrity and genetic stability, with high post-thaw recovery rates of the cryopreserved samples (Matsumoto, 2017; Santos \& Salomão, 2017). Cryopreservation protocols have turned from earlier approaches involving programmed slow cooling, which is expensive due to the cost of programmable freezing equipment, to methods based on vitrification with cryoprotectants followed by fast cooling in liquid nitrogen. However, cryoprotectants can have toxic effects and result in injuries to cells of some species (Best, 2015; Fahy, 2010). The toxicity level depends mainly on the type and concentration of the cryoprotectants used, cooling and warming rates, plant species, as well as the time of exposure of the cells to the cryoprotectant solution. Hence, one of the most critical factors in the development of protocols using vitrification techniques is stringent timing in the application and removal of cryoprotectants (Best, 2015; Fahy, 2010). 
In the present work, three different cryoprotectant solutions were applied to condition shoot tips of "Brazilian Ginseng" for cryopreservation. In all solutions tested (PVS2, PVS3 and PVS4) the highest percentage of regeneration of both control (LN-) and frozen $(\mathrm{LN}+) \mathrm{ST}$ occurred when they were treated at room temperature $\left(25 \pm 2{ }^{\circ} \mathrm{C}\right)$ for $60 \mathrm{~min}$, the highest exposure time to the cryoprotectant solution tested. These results suggest that treatment of ST with vitrification solutions for $60 \mathrm{~min}$ promoted the necessary dehydration of the explants, avoiding intracellular ice formation and growth, thus preventing irreversible damage to cell membranes and allowing their survival after exposure to liquid nitrogen (Mazur, 1984; Suranthran et al., 2012). The time of exposure to vitrification solutions affording optimal osmotic dehydration varies widely among different plant species and tissues of the explant. In the case of P. glomerata 60 min was ideal. In many studies, explants are treated with vitrification solutions at $0{ }^{\circ} \mathrm{C}$ to allow longer treatment durations, thereby reducing vitrification solution effects and increasing efficiency of the treatment to afford higher survival rates after cryopreservation (Best, 2015; Fahy, 2010). In the case of $P$. glomerata, vitrification treatment at $25{ }^{\circ} \mathrm{C}$ proved to be more efficient.

The capacity for regrowth after cryopreservation is unquestionable evidence of the structural integrity of the explant. The age and physiological status of the stock plants at the time of explant excision can influence post-cryopreservation regrowth (Harding et al., 2001; Reed, 2000). Therefore, the subculture to Magenta boxes was a step of the procedure designed to synchronize growth of $\mathrm{AB}$ and produce shoots of similar age and physiological maturity for the cryopreservation tests. Two weeks after subculture of NS, AB elongated and produced shoots $1.0-1.5 \mathrm{~cm}$ long with structures differentiated enough to facilitate handling and excision of ST. The size of the explant can also affect post-thaw recovery rates. Smaller explants tend to be homogeneous and consist of smaller, actively dividing cells with few vacuoles. Tissues with these characteristics generally have lower water contents and are more tolerant to dehydration than highly vacuolated and differentiated cells. Shoot tips, containing the apical dome and one or two leaf primordia, sized $0.5-1.0 \mathrm{~mm}$, are ideal explants for cryopreservation, not only because they are genetically stable, but also because they generally show high post-thaw recovery. The results obtained in this study indicate that the shoot tip size selected and the physiological maturity stage were appropriate, and allowed them to survive vitrification and cryopreservation in liquid nitrogen.

\section{Conclusions}

Shoot tips of Pfaffia glomerata (Spreng.) Pedersen, "Brazilian Ginseng", can be cryopreserved successfully with high regeneration rates using the vitrification technique. Shoot tips pre-cultured and treated with the loading solution did not survive freezing in liquid nitrogen, therefore treatment with a vitrification solution was essential for shoot tip survival after cryopreservation. The best regeneration percentages were obtained after treatment with the vitrification solutions PVS2 and PVS4 at $25^{\circ} \mathrm{C}$, for $60 \mathrm{~min}$. Cryopreserved shoot tips that remained viable resumed growth within a week upon transfer to growth medium and developed into normal plantlets after fifteen days after innoculation. There is no previous report of cryopreservation of $P$. glomerata, "Brazilian Ginseng", so the present work brings new and relevant information and suggest that the cryopreservation procedures described can be applied for long-term conservation of $P$. glomerata genetic resources.

\section{Acknowledgements}

The authors express their gratitude to the Brazilian Corporation for Agricultural Research-EMBRAPA for financial support to research project 0115020021304, Cryopreservation of plant genetic resources, given to Izulmé Rita Imaculada Santos, and the National Counsel for Scientific and Technological Development-CNPq for the $\mathrm{PhD}$ grant awarded to Daniela Vasconcelos de Oliveira.

\section{References}

Alves, R. B. N., Bertoni, B. W., Vieira, R. F., França, S. C., Ming, L. C., \& Pereira, A. M. S. (2010). Influência de diferentes meios de cultura sobre o crescimento de Pfaffia glomerata (Spreng.) Pedersen (Amaranthaceae) para conservação in vitro. Revista Brasileira de Plantas Medicinais, 12(4), 510-515. https://doi.org/10.1590/S1516-05722010000400016

Best, B. P. (2015). Cryoprotectant toxicity: Facts, issues and questions. Rejuvenation Research, 18(5), 422-436. https://doi.org/10.1089/rej.2014.1656

Engelmann, F. (2011). Use of biotechnologies for the conservation of plant biodiversity. In Vitro Cellular and Developmental Biology-Plant, 47, 5-16. https://doi.org/10.1007/s11627-010-9327-2

Fahy, G. M. (2010). Cryoprotectant toxicity neutralization. Cryobiology, 60, 545-553. https://doi.org/10.1016/ j.cryobiol.2009.05.005 
Flores, R., Nicoloso, F. T., Maldaner, J., \& Gartlet, T. M. B. (2009). Benzilaminopurina (BAP) e thidiazuron (TDZ) na propagação in vitro de Pfaffia glomerata (Spreng.) Pedersen. Revista Brasileira de Plantas Medicinais, 11(3), 292-299. https://doi.org/10.1590/S1516-05722009000300010

Flores, R., Brondani Jr., D., Cezarotto Jr., V., Giacomelli, S. R., \& Nicoloso, F. T. (2010). Micropropagation and $\beta$-ecdysone content of the Brazilian Ginsengs Pfaffia glomerata and Pfaffia tuberosa. In Vitro Cellular and Developmental Biology-Plant. https://doi.org/10.1007/s11627-010-9286-7

Freitas, C. S. (2003). Actions of crude hydroalcoholic extract of Pfaffia spp. on gastrointestinal tract. Brazilian Archives of Biology and Technology, 46(3), 1167-1179. https://doi.org/10.1590/S1516-89132003000300007

Freitas, C. S., Baggio, C. H., Silva-Santos, J. E., Rieck, L., Santos, C. A. M., Correa, C. J., ... Marques, M.C.A. (2004). Involvement of nitric oxide in the gastroprotective effects of an aqueous extract of Pfaffia glomerata (Spreng) Pedersen, Amaranthaceae, in rats. Life Sciences, 74, 1167-1179.

Harding, K., \& Staines, H. (2001). Biometric Analysis of phenotypic characters of tomato shoot tips recovered from tissue culture-dimethyl sulphoxide treatment and cryopreservation. Cryo Letters, 22, 255-262.

Kim, H. -H., No, N. -Y, Shin, D. -J., Ko, H. -C., Kang, J.-H.,Cho, E. -G., \& Engelmann, F. (2011). Development of alternative plant vitrification solutions to be used in droplet-vitrification procedures. Acta horticulturae, 908, 181-186. https://doi.org/10.17660/ActaHortic./2011.908.20

Leal, P. F., Kfouri, M. B., Alexandre, F. B., Fagundes, F. H. R., Prado, J. M., Toyama, M. H., \& Meireles, M. A. A. (2010). Brazilian Ginseng extraction via LPSE and SFE: Global yields, extraction kinetics, chemical composition and antioxidant activity. The Journal of Supercritical Fluids, 54, 38-45. https://doi.org/ 10.1016/j.supflu.2010.03.007

Marques, L. C., Galvão, S. M. P., Espindola, E., Dias, R. F., Mattei, R., Oliveira, M. G. M., \& Carlini, E. L. A. (2004). Psychofarmacological assessment of Pfaffia glomerata roots (extractos BNT-08) in rodents. Phytotherapy Research, 18, 566-572. https://doi.org/10.1002/ptr.1500

Martins, C. F., \& Nicoloso, F. T. (2004). Micropropagação de Pfaffia tuberosa (Spreng.) Hicken. Revista Brasileira de Plantas Medicinais, 6(3), 53-61.

Matsumoto, T. (2017). Cryopreservation of plant genetic resources: Conventional and new methods. Reviews in Agricultural Science, 5, 13-20. https://doi.org/10.7831/ras5.13

Mazur, P. (1984). Freezing of living cells: Mechanisms and implications. American Journal of Physiology-Cell Physiology, 247, 125-142. https://doi.org/10.1152/ajpcell.1984.247.3.C125

Mendes, F.R, \& Carlini, E.A. (2007). Brazilian plants as possible adaptogens: An ethnopharmacological surve of books edited in Brazil. Journal of Ethnopharmacology, 109, 493-500. https://doi.org/10.1016/j.jep.2006. 08.024

Murashige, T., \& Skoog, F. (1962). A revised medium for rapid growth and bioassays with tobacco tissue cultures. Physiologia Plantarum, 15, 473-497. https://doi.org/10.1111/j.1399-3054.1962.tb08052.x

Nakai, S., Takagi, N., Miich, H., Hayashi, S., Nishimoto, N., Takemoto, T., \& Kizu, H. (1984). Pfaffosides, nortriterpenoid saponins, from Pfaffia paniculata. Phytochemistry, 23, 1703-1705. https://doi.org/10.1016/ S0031-9422(00)83473-1

Neto, A. G., Costa, J. M. L. C., Belati, C. C., Vinholis, A. H. C., Possebom, L. S., Da Silva Filho, A. A.,... Silva, M. L. A. (2005). Analgesic and anti-inflammatory activity of a crude root extract of Pfaffia glomerata (Spreng.) Pedersen. Journal of Ethnopharmacology, 96, 87-91. https://doi.org/10.1016/j.jep.2004.08.035

Nishimoto, N., Nakai, S., Takagi, N., Hayashi, S., Takemoto, T., Odashima, S., ... Wada, Y. (1984). Pfaffosides and nortriterpenoid saponins from Pfaffia paniculata. Phytochemistry, 23, 139-142. https://doi.org/10.1016/ 0031-9422(84)83094-0

Nishimoto, N., Shiobara, Y., Fujino, M., Inoue, S-S., Takemoto, T., Oliveira, F. de, ... Matsuura, H. (1987). Ecdysteroids from Pfaffia iresinoides and reassignment of some C NMR chemical shifts. Phytochemistry, 26, 2505-2507. https://doi.org/10.1016/S0031-9422(00)83865-0

Nishimoto, N., Shiobara, Y., Inoue, S. S., Fujino, M., Takemoto, T., Yeoh, C. L., ... Hashimoto, G. (1988). Three ecdysteroid glycosides from Pfaffia iresinoides. Phytochemistry, 27, 1665-1668. https://doi.org/10.1016/ 0031-9422(88)80422-9 
Panis, B., \& Lambardi, M. (2005). Status of cryopreservation technologies in plants: Crops and forest trees. Proceedings of the 2005 conference: The Role of Biotechnology (pp. 43-54). Villa Gualino, Turin, Italy.

Rates, S. M. K., \& Gosmann, G. (2002). Pfaffia: Available chemical and pharmacological data and their implications for its therapeutic use. Brazilian Journal of Pharmacognosy, 2, 85-92. https://doi.org/ $10.1590 / \mathrm{S} 0102-695 \mathrm{X} 2002000200005$

Reed, B. (2008). Plant cryopreservation: A practical guide. New York, NY: Springer. https://doi.org/10.1007/ 978-0-387-72276-4

Sakai, A., Kobayashi, S., \& Oiyama, I. (1990). Cryopreservation of nucellar cells of navel orange (Citrus sinensis Osb. Var. brasiliensis Tanaka) by vitrification. Plant Cell Reports, 9, 30-33. https://doi.org/10.1007/ BF00232130

Sakai, A., \& Engelmann, F. (2007). Vitrification, encapsulation-vitrification and droplet vitrification: A review. Cryo Letters, 28(3), 151-172.

Santos, I. R. I., \& Salomão, A. N. (2017). In vitro germination of zygotic embryos excised from cryopreserved endocarps of Queen Palm (Syagrus romanzoffiana (Cham.) Glassman. In vitro Cellular and Developmental Biology-Plant, 53, 418-424. https://doi.org/10.1007/s11627.017.9840.7

Shiobara, Y., Inoue, S., \& Kato, K. (1993). A nortriterpenoid, triterpenoid and ecdysteroids from Pfaffia glomerata. Phytochemistry, 32(6), 1527-1530. https://doi.org/10.1016/0031-9422(93)85172-N

Suranthra, N. P., Gantait, S., Sinniah, U. R., Subramaniam, S., Alwee, S. S. R. S., \& Roowi, S. H. (2012). Effect of loading and vitrification solutions on survival of cryopreserved oil palm polyembryoids. Plant Growth Regulation, 66, 101-109. https://doi.org/10.1007/s10725-011-9633-7

Vandenbussche, B., Weyens, G., \& De Proft, M. (2000). Cryopreservation of in vitro sugar beet (Beta vulgaris L.) shoot tips by a vitrification technique. Plant Cell Reports, 19, 1064-1068. https://doi.org/ $10.1007 / \mathrm{s} 002990000232$

Volk, G. M., \& Walters, C. (2006). Plant vitrification solution 2 lowers water content and alters freezing behavior in shoot tips during cryoprotection. Cryobiology, 52(1), 48-61. https://doi.org/10.1016/j.cryobiol.2005. 09.004

\section{Copyrights}

Copyright for this article is retained by the author(s), with first publication rights granted to the journal.

This is an open-access article distributed under the terms and conditions of the Creative Commons Attribution license (http://creativecommons.org/licenses/by/4.0/). 